\title{
Emerging uses of aluminium in late 20th and early 21 st century
}

\author{
R N PARBAT \\ Indian Aluminium Co. Ltd., Calcutta 700071, India \\ Abstract. Aluminium a metal of this century will emerge as the most versatile metal with wide \\ application in transport, building and packaging sectors. Aluminium is only next to Iron and \\ Steel in its availability and wide range of electro-mechanical properties. It combines the \\ strength and toughness of steel alongwith electrical conductivity of copper. In the area of \\ energy efficient and light weight designs, aluminium and its alloys will score over all other \\ materials. The paper highlights the trend of application and their growth in the early part of \\ the next century.
}

Keywords. Aluminium; transport; building; packaging.

\section{Introduction}

The next few decades will witness the emergence of aluminium as the most versatile, effective as well as ecologically acceptable metallic element to be used on a large scale at a global level. The iron and steel family will be its only competitor in tonnage terms, although they hold predominance in the applications arena. The slow, steady but inexorable increase in the use of aluminium alloys will occur simultaneously over a range of areas. This paper attempts to provide pointers at some of the key areas where this metal will carve out a niche through technological developments and high technology inputs at each of the structure-process-property stages with resulting expansion into new applications and novel products.

\section{Use of aluminium in transportation industry}

In an increasingly competitive world, improved transportation will play a vital role. A light weight metal like aluminium will play a major role, since weight reduction directly translates to improved performance, reduced fuel consumption as well as increased range. All other parameters being equal, lower density translates directly to the same percentage of weight reduction unlike other characteristics such as strength and modules.

\subsection{Automobiles}

The dash to capture the mass market for aluminium intensive vehicles is already under way. There is a continuous search for the past forty years for light weight, fuel-efficient recyclable cars and has thus far yielded only expensive luxury sports cars. These have however successfully demonstrated the potential for aluminium structured cars. As a result of this, over the next few years, the focus will be to put a dent in the global automotive mass market. The primary barrier to achieving this has been the cost related to incorporating aluminium into high volume automotive production lines. The much higher cost of aluminium compared to its current competitor, galvanized 
steel could potentially be offset by the fact that aluminium is more than $60 \%$ lighter in gauge as compared to gauge with steel. The aim will be to convince the global car makers of the significant advantages in reducing vehicle's weight without reducing its size or comfort while reducing fuel consumption and exhaust gas emissions and in the proven recyclability of aluminium.

Aluminium is already a major contributor to the production of radiators, pistons, engine blocks, cylinder heads, intake manifolds, transmission housing and airconditioning evaporator and condenser units. Components such as disc brake rotors, disc brake callipers, cantilevers, bumper reinforcement, door impact beams, parallel flow type condensers, propeller shafts, yokes, upper arms and links and wheels are target components for aluminium alloys.

Currently aluminium alloys have $35 \%$ of the North American wheel market and as early as 1995 this figure had the potential to move up to $50 \%$. Much of the momentum for aluminium alloys making such rapid inroads in the wheel market is due to the weight savings aluminium provides, which result in improved fuel economy and handling performance. They are also able to offer numerous styling advantages. Improvements are needed in the areas of surface finish, casting methods and machining techniques and these will further aid the development of aluminium alloys as a key player in the global wheel market.

Several car makers such as Ford, Honda, Nissan and Mazda are also using aluminium body on several of their cars. In Europe today, the Land Rover vehicle, Discovery, uses aluminium for all of its exterior panels except the roof. A study commissioned by ALCAN indicated that the worldwide use of aluminium in automobiles will grow to 6.67 million tonnes by the year 2000 . It is important to note that this figure does not take into account any significant adoption in the car structure itself, known in the automobile world as the body-in-white. Significantly, it is here in the actual space frame where lies the greatest potential for aluminium, which offers unique advantages. A highly rigid manpower reduced construction system will make full use of the structural characteristics of extruded aluminium components. A variety of bending techniques such as continuous two and three dimensional bending may be applied to the extruded aluminium components including front and rear pillars, roof rails, front and rear side frames to reduce the number of joints. Improvements in diecasting technology will lead to pore free diecastings to be produced with improved strength, lighter weight and thinner walls, enabling the frame members of different sizes to be more easily joined in all directions. High speed laser welding will allow assembly of structural members at rapid rates. Thus the next few years will see a marathon effort to lower the costs involved to pave the way for a new generation of aluminium structured automobiles with broad based appeal. The aim will be to maximize aluminium's weight savings by constructing structures that can be half the weight of the current steel counterparts and yet meet all the durability and safety requirements. The area of alloy development will require inputs to develop alloys which will be tailored specifically for the weld bonding process as well as meet the formability requirement of volume automotive manufacturing. To develop aluminium as skin panels, the new alloys will need to equal or better the performance of present day bake hardened panels at perhaps slightly thicker gauges.

Currently over $85 \%$ of the aluminium used in motor vehicles is being reclaimed. With aluminium industry's record in establishing efficient recycling systems, there is reason to be optimistic about the metal's future as a key component in the environmentfriendly car. 


\subsection{Railways}

For conventional rolling stock (trains), reduced weight does not necessarily translate to improved performance. The extremely heavy weight of locomotives in excess of 225 tonnes is considered to be an advantage for traction considerations. However when high speed rail systems are considered $(>160 \mathrm{~km} / \mathrm{h})$, as is in operation in countries like France, Japan, UK and Germany with preparations under way in Spain, reduced weights begin to have many of the same advantages as in air and road systems. For example, in the series 300 Shinkansen, which is in operation on the Tokyo-Shin-Osaka-Tokkaido line in Japan, the use of aluminium mainly in the form of extrusions of newly developed alloys has resulted in a $25 \%$ weight reduction with a resulting increase in speed from $220 \mathrm{~km} / \mathrm{h}$ to $270 \mathrm{~km} / \mathrm{h}$. There are many considerations necessary in the construction of an acceptable high speed rail system. As speed increases, stability becomes an increasing concern, alongwith the related characteristics of vibration. Noise also increases, a great concern in heavily populated areas. Drag increases as the second power of speed. Secondary factors such as the capability to enter tunnels at very high speeds take on an increasingly important role. To overcome these challenges, the relationship between configuration, speed and overall performance needs to be understood first at a theoretical level. Aluminium alloys will play a dominant role in the area of trucks which need to be lightweight and bolster less to ensure the required performances in running ability and rapid passing capability on curved sections of rail under high speed operating conditions. The car-body structure will be another area where substantial weight reductions can be realized by using large size extruded sections of aluminium alloys in place of traditional steel components. Weight reduction in bogies, gear and axle boxes, window fixtures and passenger carriage fixtures such as seats will also pay dividends. After accounting for differences in strength and modules between aluminium and iron, an aluminium car body shell weighs about two-thirds of its steel counterpart. Additionally the utilization of aluminium will result in a number of other advantages. Aluminium being corrosion resistant will allow the aluminium car body to maintain their attractive appearance and will be durable without the use of protective coatings. Secondary benefits will include reduced maintenance time and consequently improved car availability. Aluminium can be readily fabricated into a variety of products while maintaining close tolerances, and this good workability will be an added advantage to its high thermal conductivity allowing effective heat dissipation from hot area such as around electrical components. In Japan aluminium structured rail cars currently account for approximately $20 \%$ of the total passenger carrying cars, and this figure is predicted to rise to $40 \%$ by the turn of the century. Technological inputs will be needed in the areas of alloy development and in the development of enhanced extrusion and pressing capabilities to allow lightweight, high strength and high rigidity cars to be made. Larger aluminium extruded parts will allow decrease in the number of manufacturing processes and the development of processes such as continuous welding will secure air tightness. The longer extrusions will also minimize the need for numerous welded joints in the body structure. This in turn will result in increased body rigidity thus producing a structure capable of withstanding the pressure when a car enters a tunnel at high speed. The leading portion of the cars may be configured with a streamlined slant nose with aluminium plate being used in the skirt area resulting in substantial weight savings in the body shell weight of the car. Gear boxes and axle boxes will increasingly be made from aluminium alloys. Apart from weight reduction, the use of aluminium will allow elimination of radiation fins due to improved 
thermal emission, as a result of which the running temperature can be reduced compared with conventional cast iron construction.

Considerable potential exists for the use of aluminium in the passenger cars themselves, again contributing to weight reduction. The seat swivel, recline, side panel as well as the boxes of electrical equipment under the floor have been almost entirely changed from steel to aluminium in present day Japanese bullet trains. The trend over the next decade will be to increase confidence in the durability of the extruded aluminium cars that are in operation today. The development of thinner extruded parts and reduced costs through material saving by reduced weight, decreasing the number of assembly steps and using easy fabrication techniques such as automated welding will allow aluminium an increased share in the advanced railway systems of the world. Aluminium honeycomb cored panels and high strength alloys will also be evaluated for possible railcar use.

\subsection{Aerospace}

The aircraft and aerospace fields cannot be considered as 'emerging' in terms of aluminium alloy usage. The reason is shown in the following table which shows the value of weight saving in various transportation systems in terms of what industry is willing to pay for a pound in weight saved.

\begin{tabular}{ll}
\hline Transportation system & Cost (US \$) \\
\hline Automobiles & 3 \\
Commercial aeroplane & 300 \\
Military aeroplane & 3000 \\
Space & 30000 \\
\hline
\end{tabular}

The advancement in this high technology area will be spearheaded by increasing use of aluminium alloy based novel materials such as discontinuous and continuous metal matrix composites (MMCs) and aerospace structures are the first major applications area for them. These advanced materials are attractive due to their enhanced specific weight, specific stiffness, wear resistance, thermal cycling capacity and controllable coefficients of thermal expansion compared to their monolithic counterparts. Aluminium alloys best fulfil three essential requirements for the selection of a composite matrix: (i) high ductility to provide strain accommodation around brittle ceramic reinforcements, (ii) low melting point to allow liquid phase fabrication processes without impairing the fibre reinforcement properties and (iii) low density to allow high specific properties.

For a given successful application, the following major steps have to be negotiated: (I) Reinforcement development, optimization and high volume production, (II) metal matrix composites process development, (III) matrix metallurgy optimization and (IV) acceptance of design criteria specific to MMCs.

To fulfill the above-mentioned prerequisites, a large range of manufacturing routes have been found to be promising. The fabrication processes for aluminium alloy MMCs can be broadly classified under three areas: 
(i) Powder metallurgy: This includes the processes of compaction and sintering, hot pressing, mechanical alloying, rapid solidification techniques and plasma spraying.

(ii) Liquid metallurgy: The techniques of stir casting, rheocasting, squeeze casting, liquid metal infiltration and directional solidification are included within this.

(iii) Secondary processing: Hot pressing, extrusion and rolling are working processes which may be included under this.

For structural grade aluminium composites, powder metallurgy will be used to consolidate rapidly solidified aluminium alloys with high strength ceramics such as silicon carbide $(\mathrm{SiC})$. Higher directional strengths may be established in finished composites through rolling, forging, extrusion and superplastic forming. The fabrication of high strength structural grade MMC parts in one operation will aim to cut manufacturing costs and simplify secondary processing requirements, together with this, it should be possible to obtain section thicknesses less than those obtained with unreinforced materials resulting in significant weight savings.

Space instrument grade aluminium composites will be produced using powder metallurgy processes using particulate ceramic reinforcements to obtain isotropic properties. Precision components for inert guidance systems is one example of use of instrument grade MMCs. The components will be precision forged to near net shape requiring microstructural control to maintain optimum size and separation of ceramic particles. The fine particles will preserve the fine grain structure at elevated temperatures for increased resistance to creep.

Metal mirror optics will use optical grade MMCs. The distinguishing characteristics of these MMCs will include a modified matrix alloy chemistry and ceramics particle size distribution as well as a higher content of dispersed oxide. These will also have to undergo optimized homogenization and precipitation heat treatments. The composites will retain the unique ability to tailor the coefficient of thermal expansion to match that of currently used materials such as beryllium. Stainless steel, copper and electroless nickel selecting the appropriate volume fraction of particulate reinforcement. By selecting the reinforcement content for an MMC mirror substrate, it will be possible to optimize stiffness and micro-creep resistance as well as match the coefficient of thermal expansion of the plating deposited on the reflective surface. The design requires a high value of micro-yield strength along with low density since the mirror is subjected to significant forces during boost phase and earth orbital manoeuvre. It ought to be mentioned that the uses of MMCs are fast expanding not only in aerospace and aircraft, but also in the areas of automobiles, electronic packaging and sports and leisure goods.

\section{Aluminium in building infrastructure}

The construction industry in the USA currently consumes a quarter of the nation's aluminium output. Aluminium is currently used to sheathe the World Trade Centre in New York. Contractors use aluminium nails, screws and bolts to install aluminium storm doors, screens, flashing, gutters, down spouts, shingles, awnings and venetian blinds - some 200 building products in all. It is also currently used in bridge railings, light standards, highway barriers, sewage treatment plants and water systems and has 
the credentials to play a larger role in this huge and growing market. The high specific strength, durability, corrosion resistance, amenability to every metal working process, electrical and thermal amenability to every metal working process, electrical and thermal conductivity, availability in many forms and alloys and recyclability will allow it to perform in a broader dimension. Aluminium extractions will be able to simplify repair of worn out bridge decks. Steel decking weighs about $75 \mathrm{lbs}$ per square $\mathrm{ft}$ compared with $25-40$ for aluminium. This weight advantage reduces dead load, often avoiding the need to replace original structural elements when retrofitting an aluminium deck.

Light weight also increases the bridge's live load capacity making it possible to increase bridge capacity. Aluminium orthotropic bridge decks being prefabricated, a complete decking system can be shipped to the bridge for immediate on-site installation. What normally takes approximately a month can be done in a week. The properties of aluminium will be a cost cutting factor and help to overcome steel's cost advantage. To hasten the acceptance of aluminium for this application the following points ought to be attended to: (i) fatigue testing of a full sized bridge deck under laboratory conditions, (ii) monitoring of actual installations to record performance characteristics, (iii) improved design to optimize fabrication and installation, (iv) development of criteria for balancing total life cycle saving against first cost and (v) education of designers and specifiers in the advantages of aluminium.

A potential market of 300 million pounds of aluminium exists in this area.

Deployable (transformable) structures is another emerging area for aluminium use. For example, a complex aluminium structure formed by 6475 pieces weighing 10 tonnes with 1242 square metres of structural area was built in a Venezuelan factory with factory tolerances and quality and then shipped 5235 miles away to be successfully erected in two days.

The main advantages of deployable structures are their reusability, the small volume they occupy during storage and transportation and the ease and speed of erection. Implicitly, the deployable structures of the future will have a far broader range of applications as even before; in architecture, construction and aerospace industries. They can serve either as once only deployed frameworks of stationary objects or, more often, can be put to recurring uses, passing various cycles of deployment, collapsing and transportation. The repetitive utilization of deployable structures may include emergency facilities such as shelters, bridges and hangars, exposition pavilions, grandstands, sports facilities as well as various types of domed, vaulted and plane space trusses. In outer space, the single, deploying operations are considered for the main framing, support systems and manned stations and laboratories. There is need at this stage to carry out studies that are directly related to the development, planning and erection of usable and easily buildable economical structures resisting the whole range of transportation and service loads. Aluminium is the first choice for the manufacturing of these structures due to its particular properties. Its low density will permit obtaining lighter pieces to simplify transportation and handling. Its resistance to corrosion and unfavourable climatic conditions also enhance its candidacy as the primary metal choice. The use of perforated cladding systems which currently is very limited is set to expand over the coming years. Painted aluminium sheets will be used for industrial and commercial buildings not only to provide insulation but also to allow additional heating. This will result in significant energy saving as well as lower heating and cooling costs for building owners. In specialized areas such as this, alternative 
materials may not be able to provide the right mix of properties such as corrosion resistance and thermal properties. This will therefore be another frontier for aluminium profiled sheet.

\section{Aluminium in packaging industry}

The use of aluminium in the food and drug industry will expand due to its proven non toxic, non absorptive and splinter proof properties. It also minimized bacterial growth, forms colourless salts and can be steam cleaned. Low volumetric specific heat results in economies when containers or conveyors must be moved in and out of heated or refrigerated areas. The non sparking property of aluminium will be of value in flour mills and other plants that are subject to fire and explosion hazards. Its corrosion resistance will allow it to ship fragile merchandise, valuable chemicals and cosmetics. It is expected that packaging will be one of the fastest growing markets for aluminium through products such as household wrap, flexible packaging, food containers, bottle caps. collapsible tubes and food and beverage cans.

The recyclability of aluminium beverage cans have been a major reason for the gaining popularity in the USA and Europe. This is revealed by the statistic that in Europe in $1988,40 \%$ of beverage can production was accounted for by aluminium, whereas the corresponding figure for 1992 was $51 \%$. In the LSA, aluminium already holds $98 \%$ of the can market where the current recyclability figure is $68 \%$. Environmental considerations are high on the agenda in most developed countries and aluminium will be increasingly welcomed as the solution to the two-fold problem of higher waste output and declining landfill site availability. In countries like Sweden, where aluminium already enjoys a $100 \%$ market share, a voluntary collection programme has brought the aluminium can recycling rate to $86 \%$. Similar thinking has resulted in the corresponding figure in Switzerland to be $68 \%$. In the coming decades, huge emerging markets like India and China will further bolster demand for aluminium beverage cans and see it emerge as the market leader well into the next century.

The litter and landfills of our throwaway society stand as a reproach to a way of life we know to be both wrong and immensely costly. The role of aluminium will be to act as the catalyst for the recycling society that will soon be upon us. When aluminium is recycled, we save $95 \%$ of the energy needed to make new metal from bauxite. Aluminium is therefore an effective energy bank that can be tapped over and over again. Although the largest single source of scrap aluminium is still beverage cans, this is likely to change through the introduction of new magnetic separation techniques which will utilize the non magnetic nature of aluminium to separate it from an assortment of metallic refuse in a controlled manner and collect it in containers. Thus aluminium will be able to come close to if not fully realize the vision of a society expressed by the Nobel Laureate Glenn T. Seaborg where "the present materials situation is literally reversed; all waste and scrap - what are now called secondary materials-become our major resources, and our natural, untapped resources become our backup supplies". In this scenario aluminium may play one, two or perhaps three roles. 